\title{
Performance Evaluation of a Very-low-volume Sampler for Atmospheric Particulate Matter
}

\author{
Maria Catrambone $^{1}$, Silvia Canepari ${ }^{2}$, Marina Cerasa ${ }^{1}$, Tiziana Sargolini ${ }^{1}$, Cinzia Perrino $^{1 *}$ \\ ${ }^{1}$ C.N.R. Institute of Atmospheric Pollution Research, 00015 Rome, Italy \\ ${ }^{2}$ Department of Chemistry, Sapienza University of Rome, 00185 Rome, Italy
}

\begin{abstract}
A cheap and small device for sampling atmospheric particulate matter (PM) has been recently developed. It works at a very low flow rate $\left(0.5 \mathrm{~L} \mathrm{~min}^{-1}\right)$ and is able to collect the atmospheric aerosol on filters, allowing subsequent chemical analyses. The samplings have a long duration (1-2 months), and the devices can be used to make cheap networks over a territory. These very-low-volume samplers (VLVS) can be used to trace long-term concentration variations and to draw up concentration maps of PM and its chemical components.

The performance of the VLVS was evaluated in terms of measurement repeatability and of agreement with the results obtained when using a $2.3 \mathrm{~m}^{3} \mathrm{~h}^{-1}$ reference sampler (REF). The study period was 1 year. The considered PM components were ions, polycyclic aromatic hydrocarbons (PAHs), levoglucosan and elements.

The repeatability of the measurements was very good for all the examined PM components: the standard deviation of 3 replicates (co-located samplers) over 9 measurement periods was in the range $2.0-5.5 \%$ for ions, $10-17 \%$ for $\mathrm{PAH}, 5.2 \%$ for levoglucosan and 5.6-16\% for elements. It was $8.2 \%$ for the PM mass concentration. This satisfactory performance indicates that the VLVSs can be reliably used to evaluate the spatial variability and to draw concentration maps of PM and PM components.

A very good agreement with the reference sampler was obtained for ions, with the only exception of ammonium nitrate and ammonium chloride (VLVS values were up to 10-20\% lower than the reference values), levoglucosan and elements. In the case of PAH, instead, the ratio VLVS/REF was in the range 1.2-1.6 for 4-ring congeners and 0.4-0.8 for 5- and 6ring congeners. For all the congeners, anyway, these typical ratios were kept, with small variations, during the whole study period.
\end{abstract}

Keywords: Validation; Sampling artifacts; Sampling duration; Spatial distribution; Concentration maps.

\section{INTRODUCTION}

Atmospheric pollution and, in particular, pollution due to particulate matter (PM), is a tricky problem, characterized by complex processes and different temporal dynamics. For this reason, in scientific studies and monitoring activities concerning PM the choice of the time duration of the observations is a critical issue.

In the European Countries most of PM measurements last for 24 hours, in compliance with the European legislation. According to the European Standard EN 12341 (2014). PM must be sampled on filters at the flow rate of $2.3 \mathrm{~m}^{3} \mathrm{~h}^{-1}$, over a nominal sampling period of $24 \mathrm{~h}$ that is generally interpreted as from midnight to midnight. During this time

\footnotetext{
* Corresponding author.

Tel.: +39 0690672263; Fax: +390690672660

E-mail address: perrino@iia.cnr.it
}

period, which includes both day and night time hours, relevant changes in the meteorological parameters may occur, causing variations in the concentration and chemical composition of the atmospheric aerosol that cannot be caught by 24-h measurements. The same holds for the fast variations in particle emission rate.

A sampling duration of 24 hours also involves the possible occurrence of sampling artifacts due to the prolonged exposure of the collected particles to the incoming air flow (release of semi-volatile species, adsorption of gaseous components, chemical reactions among the collected species or between the particles and the filter) (Vecchi et al., 2009 and cited therein). In these cases, even if the analytical determinations adequately quantify the main chemical species in the collected aerosol and the mass closure is obtained, the chemical composition of the analysed sample may not represent the real chemical composition of atmospheric PM. Moreover, the volatilized species, not considered for compliance with the concentration limits, may nevertheless be responsible for environmental and health effects. 
To overcome these limitations of filter-based analysis, in the last twenty years many on-line techniques have been developed, generally characterized by rapid time response (seconds -1 hour) and minimum sample handling (Chow et al., 2008). These techniques (optical particle counters, Aerosol Mass Spectrometers, Particle-Into-Liquid-Sampler, Particle-Induced X-ray Emission, among others) provide an accurate photograph of atmospheric pollution events and allow a better understanding of their dynamics (Nava et al., 2002; Costabile et al., 2017). However, they are generally expensive and require skilled personnel for the interpretation of the huge amount of data they produce. For this reason high-time-resolution techniques are not suitable for long-term monitoring of the air concentration of PM and PM chemical components.

At the other side of the sampling duration scale we find long-duration measurements (weeks to months). These are not able to give information about the processes governing atmospheric pollution but they can be very useful in tracing the long-term variations of pollutants with affordable instrumental and analytical costs. This approach has been successfully implemented by diffusive samplers, developed in the nineties and used for the evaluation of long-term concentration variations and spatial variability of gaseous pollutants (Marć et al., 2015; McAlary et al., 2015).

In this paper we report the performance evaluation of a new very-low-volume sampler (VLVS), specifically designed to determine the long-term variations and spatial variability of the concentration of PM and its components. The sampler is based on the well-consolidated sampling technique on filter media. These devices are cheap enough to be set on the territory in a high number of units at affordable cost. Consequently, they can be used to draw up detailed concentration maps able, among others, to determine the strength of local pollution sources (Massimi et al., 2017). So far, concentration maps have been derived for gaseous pollutants and for particle number and particle mass concentration, while it would be very beneficial to obtain these spatial information also for PM chemical components (Hasenfratz et al., 2015; Rohde and Muller, 2015).

The present study was aimed to evaluate: - the repeatability of the measurements of the atmospheric concentration of PM and of some of its chemical components when the sampling is carried out by using the VLVS; - for the same species, the difference in the concentration calculated when sampling with the VLVS and when using traditional instruments operating at the flow rate of $2.3 \mathrm{~m}^{3} \mathrm{~h}^{-1}$; - the existence and extent of possible artifacts occurring when the sampling is carried out by the VLVS.

\section{EXPERIMENTAL}

\section{Sampling Site and Sampling Procedure}

The VLVS sampler used in this study is the Smart Sampler (FAI Instruments, Fonte Nuova, Rome, IT), a small device $(19 \times 24 \mathrm{~cm})$ operating at the flow rate of $0.5 \mathrm{~L} \mathrm{~min}^{-1}$ (Fig. 1). Basically, the sampler consists of a small solar panel with a rechargeable battery, a shield to protect the device from rain, a micro-pump, an impactor, a

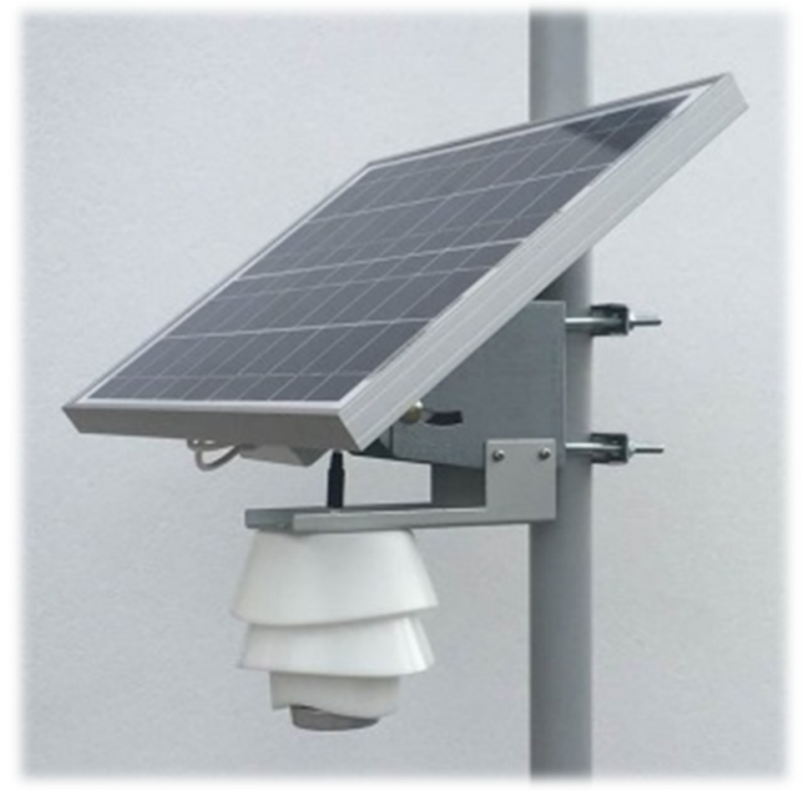

Fig. 1. Picture of the VLVS (Smart Sampler) equipped with the solar panel.

filter holder accommodating filters (37 $\mathrm{mm}$ in diameter) and a SD card to record sampling parameters. In the configuration used for this work the sample was equipped with a $\mathrm{PM}_{10}$ sampling head and was directly connected to the electric power (the solar panel was not used).

The study was carried out at the facilities of the Institute of Atmospheric Pollution Research of the National Research Council of Italy (Research Area RM1, Montelibretti, Rome, Google coordinates: $\left.42^{\circ} 06^{\prime} 20.55^{\prime \prime} \mathrm{N} ; 12^{\circ} 38^{\prime} 24.53^{\prime \prime} \mathrm{E}\right)$ and had the duration of one year (August 2016-July 2017).

During the whole study, PM samplings were carried out side by side using nine VLVSs (long period) and one reference sampler operating on a $24-\mathrm{h}$ basis (SWAM 5a Dual Channel Monitor, FAI Instruments, Fonte Nuova, Rome, IT). In order to collect enough PM mass, we decided to run the VLVSs for 6 weeks during the period AugustOctober and March-July, and 4 weeks during the period November-March, when the concentration in the study area generally increases. The choice of these time durations was based on the average concentrations detected at the site during the last ten years.

The nine VLVSs placed in the field were equipped as follows:

- 3 with Teflon filters (PTFE membrane filters with ring, $37 \mathrm{~mm}, 2.0 \mu \mathrm{m}$ pore size, Whatman), aimed at determining the mass concentration of PM by the gravimetric procedure;

- 3 with quartz filters (QM-A quartz filters, $37 \mathrm{~mm}$, Whatman), aimed at determining elements, ions and levoglucosan; after the sampling these filters where cut into two halves, the first one (A) aimed at measuring elements by inductively-coupled plasma mass spectrometry (ICP-MS), the other one (B) at measuring anions and cations by ion chromatography (IC) and levoglucosan by high-performance anion exchange 
chromatography with pulsed amperometric detection (HPAEC-PAD);

- 3 with quartz filters, aimed at determining polycyclic aromatic hydrocarbons (PAHs) by high-resolution gas chromatography coupled with mass spectrometry (HRGC-MS).

The reference sampler was equipped with $47 \mathrm{~mm}$ quartz filters. The daily concentration of PM was determined by the beta attenuation method. In order to reduce the costs of the analytical phase, before the extraction the 365 daily samples were grouped as described below. By following this procedure, the number of analyses was reduced but the representativeness of the daily samples was maintained, and, for each analysis, the amount of analysed PM was comparable to the amount analysed for the VLVSs.

The daily reference samples were treated as follows:

- every filter was cut into four sections: A, B, C, D; the area of each $A$ slice was $1 / 8$ of the total; the area of each slice B was $1 / 4$ of the total; the area of each section $\mathrm{C}$ was half of the total; the last slice $\mathrm{D}$ of each filter (1/8 of the total area) was set aside and used for possible replacements;

- sections A of the first seven sampled filters, corresponding to a sampling duration of one week, were extracted all together and analysed for their elemental content; the same procedure was applied to sections B, addressed to the analysis of ions and levoglucosan, and to sections $\mathrm{C}$, addressed to the analysis of the $\mathrm{PAH}$ content;

- the procedure was repeated for the subsequent 51 weeks of the study; the results obtained from the analysis of the pooled weekly samples were averaged to be in agreement with the results of the VSBSs (four weeks or six weeks).

A general view of how the samples were collected, subdivided, pooled and analysed is shown in Fig. 2.

Additional size-segregated samplings were carried out by using a Uniform Deposition Impactor (MOUDI; mod. 110.R, MSP) operating at the flow rate of $30 \mathrm{~L} \mathrm{~min}^{-1}$ and having cut-sizes of $0.18,0.32,0.56,1.0,1.8,3.2,5.6,10$ and $18 \mu \mathrm{m}$ in aerodynamic diameter. The MOUDI was equipped with Teflon filters.

\section{Analytical Procedure}

For elemental analysis, the appropriate section of the
VLVS samples and of the pooled reference samples (sections A) were microwave digested with $8 \mathrm{ml}$ of $\mathrm{HNO}_{3}$ $(65 \% \mathrm{w} / \mathrm{w})$ and $\mathrm{H}_{2} \mathrm{O}_{2}(30 \% \mathrm{w} / \mathrm{w}) 3: 1$ solution, diluted to $100 \mathrm{ml}$ with ultra-pure water and analyzed by ICP-MS (XSERIES 2 ICP-MS, Thermo Scientific) for their elemental content (Al, Cd, Cs, Cu, Fe, K, Mo, Pb, Rb, V).

For IC and HPAEC-PAD analysis, the appropriate section of the VLVS samples and of the pooled reference samples (sections B) were extracted in deionized water and analyzed for anions (chloride, nitrate, sulphate) and cations (sodium, ammonium, potassium, magnesium, calcium) by ion chromatography (ICS1000, Dionex Co., CA, U.S.A.). These solutions were also analysed for levoglucosan by HPAEC-PAD using a Dionex DX-500 series ion chromatograph equipped with a DC ICS-3000 oven, a GP40 Gradient Pump, and a CarboPac ${ }^{\mathrm{TM}}$ PA10 analytical column and guard column. The electrochemical detector was a Dionex ED50/ED50A Electrochemical Cell equipped with disposable gold electrodes.

For PAH analysis, the VLVS samples and the appropriate section of the pooled reference samples (sections C) were spiked with perdeuterated PAHs used as internal standard (L429-IS Internal Standard Stock Solution, Wellington Laboratories), then they were extracted in ultrasonic bath (three times, $30 \mathrm{~min}$ ) with a mixture of dichloromethane/acetone $4: 1 \mathrm{v} / \mathrm{v}$. The sample extracts were concentrated under a gentle stream of nitrogen, then purified by a silica/alumina microcolumn. The aliphatic fraction was eliminated through elution with hexane; PAHs were eluted by hexane:dichloromethane $(1: 1 \mathrm{v} / \mathrm{v})$ and analyzed by GC-MS operating in single ion monitoring mode (Ultra Trace gas chromatograph coupled to TSQ mass spectrometer, Thermo Scientific). In order to calculate the extraction and purification recovery, $50 \mathrm{ng}$ of recovery standard (L429-RS Recovery Standard Stock Solution, Wellington Laboratories) were added before injection. The following PAHs were considered: fluoranthene, pyrene, benz(a)anthracene, chrysene, benzo $(b+j+k)$ fluoranthene, benzo(e)pyrene, benzo(a)pyrene, dibenz(a,h)anthracene, indeno(1,2,3,c,d)pyrene, benzo(g,h,i)perylene.

The gravimetric determination of the mass collected on VLVS Teflon filters was carried out by using an automated microbalance ( $1 \mu \mathrm{g}$ sensitivity, mod. ME5, Sartorius AG, Goettingen, Germany), after conditioning at 50\% R.H. and $20^{\circ} \mathrm{C}$ for 48 hours. In most cases the measurement was
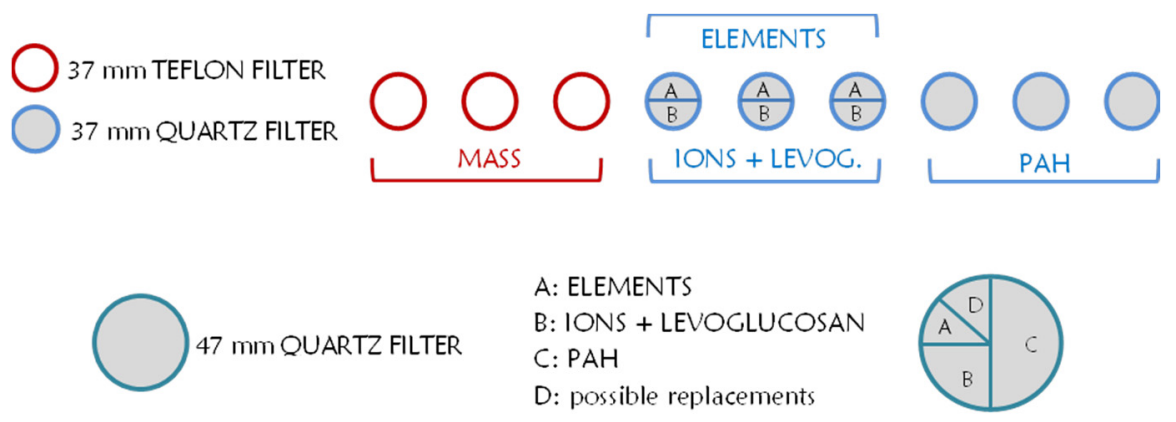

Fig. 2. Overview of the method for collection, partition, pooling and analysis of the filters: VLVSs (upper picture) and reference sampler (lower picture). 
repeated 3 times; in case the variation between two results exceeded $5 \mu \mathrm{g}$, the measurements were carried out two times more. PM mass concentration of the daily reference samples was determined by the beta attenuation method.

\section{RESULTS AND DISCUSSION}

The repeatability of the measurements of the ionic species, levoglucosan, elements, IPA and PM mass carried out on the samples collected by the VLVSs is shown in Table 1. The repeatability is expressed as the per cent standard deviation of the results obtained by the 3 co-located VLVSs and takes into account both the sampling step (sampled volume) and the analytical steps (analyte amount). Table 1 reports the mean, minimum and maximum values of the repeatability obtained during the 9 measurement periods as well as the concentration range of each compound during the study year (minimum and maximum values). The repeatability is also shown, as error bars, in Figs. 3, 5, 6, 7 and 8.

Considering the sampling step only, the repeatability was in the range $0.06-0.12 \%$ (mean value: $0.09 \%$ ). In this case, it was calculated as the per cent standard deviation of the volumes sampled by all the 9 co-located VLVSs during the 9 measurement periods ( 4 or 6 weeks; sampled air volumes from 21.7 to $35.5 \mathrm{~m}^{3}$ ). These very satisfactory results indicate that the poorer repeatability obtained for the concentrations values (Table 1) depends almost completely on the performance of the analytical step (repeatability of the analytic procedures).

\section{Inorganic Anions and Cations}

The repeatability of the measurements (Table 1) was very good for all the considered ions: the mean values referring to the whole study were below $6 \%$ for all species and around $2 \%$ in the case of sulphate and ammonium. These good results indicate that the samplings carried out by the VLVSs are very repeatable, an essential prerequisite before using these devices for evaluation the spatial distribution of PM components.

The comparison between the VLVSs (average of the results obtained by the three co-located samplers) and the

Table 1. Repeatability of the measurements carried out by the 3 co-located VLVSs: mean, minimum and maximum values of the per cent standard deviation obtained during the 9 measurement periods; concentration range during the 1-year study period $\left(\mathrm{ng} \mathrm{m}^{-3} ; \mu \mathrm{g} \mathrm{m}^{-3}\right.$ for $\mathrm{PM}_{10}$ ); ratio $\overline{\mathrm{R}}$ between the yearly average concentrations yielded by the two systems (VLVS/REF).

\begin{tabular}{|c|c|c|c|c|c|c|}
\hline & \multicolumn{3}{|c|}{$\%$ ST. DEV. } & \multicolumn{2}{|c|}{ CONCENTRATION } & \multirow{2}{*}{$\overline{\mathrm{R}}$} \\
\hline & MEAN & MIN. & MAX. & MIN. & MAX. & \\
\hline $\mathrm{Cl}^{-}$ & 5.5 & 2.1 & 11 & 97 & 520 & 0.84 \\
\hline $\mathrm{NO}_{3}^{-}$ & 3.3 & 1.3 & 5.9 & 900 & 3650 & 0.89 \\
\hline $\mathrm{SO}_{4}=$ & 2.3 & 1.0 & 3.8 & 1240 & 2840 & 1.0 \\
\hline $\mathrm{Na}^{+}$ & 4.8 & 0.1 & 13 & 230 & 950 & 0.95 \\
\hline $\mathrm{NH}_{4}^{+}$ & 2.0 & 1.0 & 4.3 & 350 & 860 & 0.96 \\
\hline $\mathrm{K}^{+}$ & 4.3 & 1.6 & 7.3 & 120 & 870 & 1.0 \\
\hline $\mathrm{Mg}^{++}$ & 5.1 & 1.7 & 11 & 38 & 110 & 0.95 \\
\hline $\mathrm{Ca}^{++}$ & 5.3 & 1.3 & 10 & 350 & 720 & 1.1 \\
\hline fluoranthene & 11 & 4.1 & 25 & 0.061 & 0.47 & 1.52 \\
\hline Pyrene & 10 & 1.9 & 17 & 0.040 & 0.48 & 1.56 \\
\hline benz(a)anthracene & 12 & 6.2 & 20 & 0.010 & 0.34 & 1.04 \\
\hline Chrysene & 16 & 4.5 & 38 & 0.015 & 1.8 & 1.20 \\
\hline benzo $(b+j+k)$ fluoranthene & 15 & 5.3 & 31 & 0.029 & 3.9 & 0.79 \\
\hline benzo(e)pyrene & 16 & 8.6 & 26 & 0.029 & 1.6 & 0.52 \\
\hline benzo(a)pyrene & 17 & 5.6 & 37 & 0.009 & 0.76 & 0.43 \\
\hline $\operatorname{dibenz}(\mathrm{a}, \mathrm{h})$ anthracene & 13 & 0.1 & 26 & 0.006 & 0.45 & 0.67 \\
\hline indeno( $(1,2,3-c, d)$ pyrene & 16 & 3.8 & 31 & 0.026 & 1.5 & 0.53 \\
\hline benzo(ghi)perylene & 15 & 4.7 & 30 & 0.027 & 2.0 & 0.60 \\
\hline levoglucosan & 5.2 & 0.5 & 10 & 19 & 490 & 1.03 \\
\hline $\mathrm{Al}$ & 16 & 10 & 22 & 41 & 330 & 1.01 \\
\hline $\mathrm{Cd}$ & 7.6 & 3.3 & 16 & 0.06 & 0.18 & 0.99 \\
\hline Cs & 9.8 & 5.5 & 17 & 0.09 & 0.22 & 0.99 \\
\hline $\mathrm{Cu}$ & 9.0 & 2.8 & 16 & 4.0 & 7.6 & 1.02 \\
\hline $\mathrm{Fe}$ & 7.9 & 2.7 & 12 & 120 & 270 & 0.99 \\
\hline K & 5.6 & 4.9 & 6.4 & 210 & 1060 & 0.97 \\
\hline Mo & 11 & 6.4 & 21 & 0.41 & 1.8 & 1.02 \\
\hline $\mathrm{Pb}$ & 6.6 & 3.5 & 11 & 1.6 & 6.3 & 1.04 \\
\hline $\mathrm{Rb}$ & 8.2 & 3.2 & 11 & 0.45 & 3.4 & 1.02 \\
\hline V & 8.7 & 6.5 & 13 & 0.76 & 2.2 & 1.03 \\
\hline $\mathrm{PM}_{10}$ & 8.2 & 3.0 & 13.4 & 14.5 & 35.6 & 0.84 \\
\hline
\end{tabular}


reference sampler (average of the daily concentration values during the considered period) for the measurement of the ionic species is shown in Fig. 3.

To assess the performance of the VLVSs in determining inorganic ions, it is necessary to consider both the thermal stability and the size distribution of each species.

Ammonium chloride and ammonium nitrate are the inorganic salts whose stability is mostly affected by variations in the thermodynamic conditions during the sampling (temperature, relative humidity, which regulate the deliquescence of these salts) and that may easily release their gaseous precursors during the sampling step. Previous studies have shown that the volatile fraction may be released during the sampling period only and that the amount remained on the filter at the end of the sampling is stable (Ashbaugh and Eldred, 2004; Perrino et al., 2012). In the literature it is also reported that the linear velocity of the air mass passing through the filter does not affect ammonium nitrate volatilization, while the duration and the start time of the sampling may have an effect (Ashbaugh and Eldred, 2004; Vecchi et al., 2009). For these species we could thus expect a difference between the results obtained when sampling for 1 day and for 1-1.5 months.

Concerning the size distribution, possible differences in the cut-off curve of the impactors may influence the species that are mainly contained in the fraction of PM around $10 \mu \mathrm{m}$ in aerodynamic diameter. To evaluate the size distribution of the ionic species we can refer to the data reported in Fig. 4. Here we compare the size distribution obtained from size-segregated samplings carried out during the summer and the winter season at the same site of this study, by using a 10-stage MOUDI impactor. Summer samplings were carried out from June $21^{\text {st }}$ to July $10^{\text {th }}$ 2017, when the mean $\mathrm{PM}_{10}$ concentration was $22.7 \mu \mathrm{g} \mathrm{m}^{-3}$; winter samplings were carried out from January $23^{\text {rd }}$ to $31^{\text {st }}$ 2018, a period of atmospheric stability, when the mean $\mathrm{PM}_{10}$ concentration was $43.1 \mu \mathrm{g} \mathrm{m}^{-3}$.

As expected, each ionic species shows its proper size distribution (Canepari et al., 2019 and cited therein). Some species that are produced by atmospheric reactions (ammonium, sulphate) are found almost exclusively in the accumulation mode of PM (below $2.5 \mu \mathrm{m}$ ). Some other species (sodium, magnesium) are mainly distributed in the coarse size fraction (above $2.5 \mu \mathrm{m}$ ), in agreement with their marine main source. The size distribution of nitrate shows a seasonal variability: during the warm periods of the year this species can be found mainly in the coarse fraction (re-suspension of soil dust; reaction between nitric acid and sodium chloride leading to the formation of sodium nitrate); during winter periods of atmospheric stability, instead, the amount in the fine fraction, due to the formation of ammonium nitrate, increases and often prevails. A similar seasonal pattern is shown by chloride, released by sea spray during all the year and produced by secondary reactions as ammonium chloride during cold periods characterised by atmospheric stability. Also potassium shows a bi-modal distribution that reflects its two main sources: biomass combustion (wild fires and domestic heating, much more important during the winter period) for the fine fraction and soil re-suspension (prevailing during the summer) for the coarse fraction. Calcium, mainly generated through erosion and soil dust re-suspension, shows a size distribution in the coarse fraction of PM, characterized by a relevant contribution in the fraction above $10 \mu \mathrm{m}$.

The results of the comparison between VLVSs and reference sampler are expressed as the ratio $\bar{R}$ between the yearly average concentrations yielded by the two systems (VLVS/REF). The values of $\overline{\mathrm{R}}$ for all the considered species are reported in the last column of Table 1.

Very good results were obtained for sulphate, sodium, ammonium, potassium and magnesium $(\overline{\mathrm{R}}$ between 0.95 and 1.0). All these species are non-volatile and characterised by a size distribution in the fine fraction of PM or in the coarse fraction but with a negligible contribution of particles greater than $10 \mu \mathrm{m}$ in diameter. Lower $\overline{\mathrm{R}}$ values were recorded for nitrate $(\overline{\mathrm{R}}=0.89)$ and chloride $(\overline{\mathrm{R}}=0.84)$, with the highest difference recorded during the winter months. These dissimilar results can be interpreted as a different behaviour of the two systems in retaining volatile ammonium salts, mainly due to the very different duration of the sampling periods.

In the case of calcium, instead, the concentrations obtained by using the VLVSs were slightly higher than those yielded when using the reference sampler $(\overline{\mathrm{R}}=1.1)$. This might be due to a different performance of the $\mathrm{PM}_{10}$ impactors: it is plausible that the impactors of the VLVSs, which operate at a flow rate about 80 times lower than the reference sampler, have a different, less sharp cut-off curve.

It is worth noting that the small differences between the results obtained by using the VLVSs and the reference sampler in the determination of ions do not impair the use of the VLVSs in homogeneous measurement networks, where the main required feature is the repeatability of the samplings.

\section{Polycyclic Aromatic Hydrocarbons}

Ten PAH congeners, having 4 condensed rings (fluoranthene, pyrene, benz(a)anthracene, chrysene), 5 condensed rings (benzo $(\mathrm{b}+\mathrm{j}+\mathrm{k})$ fluoranthene, benzo(e)pyrene, benzo(a)pyrene, dibenz(a,h)anthracene) and 6 condensed rings (indeno(1,2,3-c,d)pyrene, benzo(ghi)perylene) have been considered in this study. For benzo(a)pirene, classified as human carcinogen (class 1) by the International Agency for Research on Cancer (IARC), the European Directive 2008/50/EC has set a target value of $1 \mathrm{ng} \mathrm{m}^{-3}$ (yearly average).

The repeatability of the measurements for the ten individual PAH congeners, expressed as standard deviation of the results obtained by the three co-located samples, was in the range $11 \%-17 \%$ (average data referring to the whole study period). The standard deviation for the sum of the ten congeners was $8.7 \%$. Considering the very low concentrations and the complexity of the analytical procedure, these results are to be considered as very good and confirm those obtained for the ionic species.

The comparison between the VLVS (average of the results obtained by the three co-located samplers) and the 


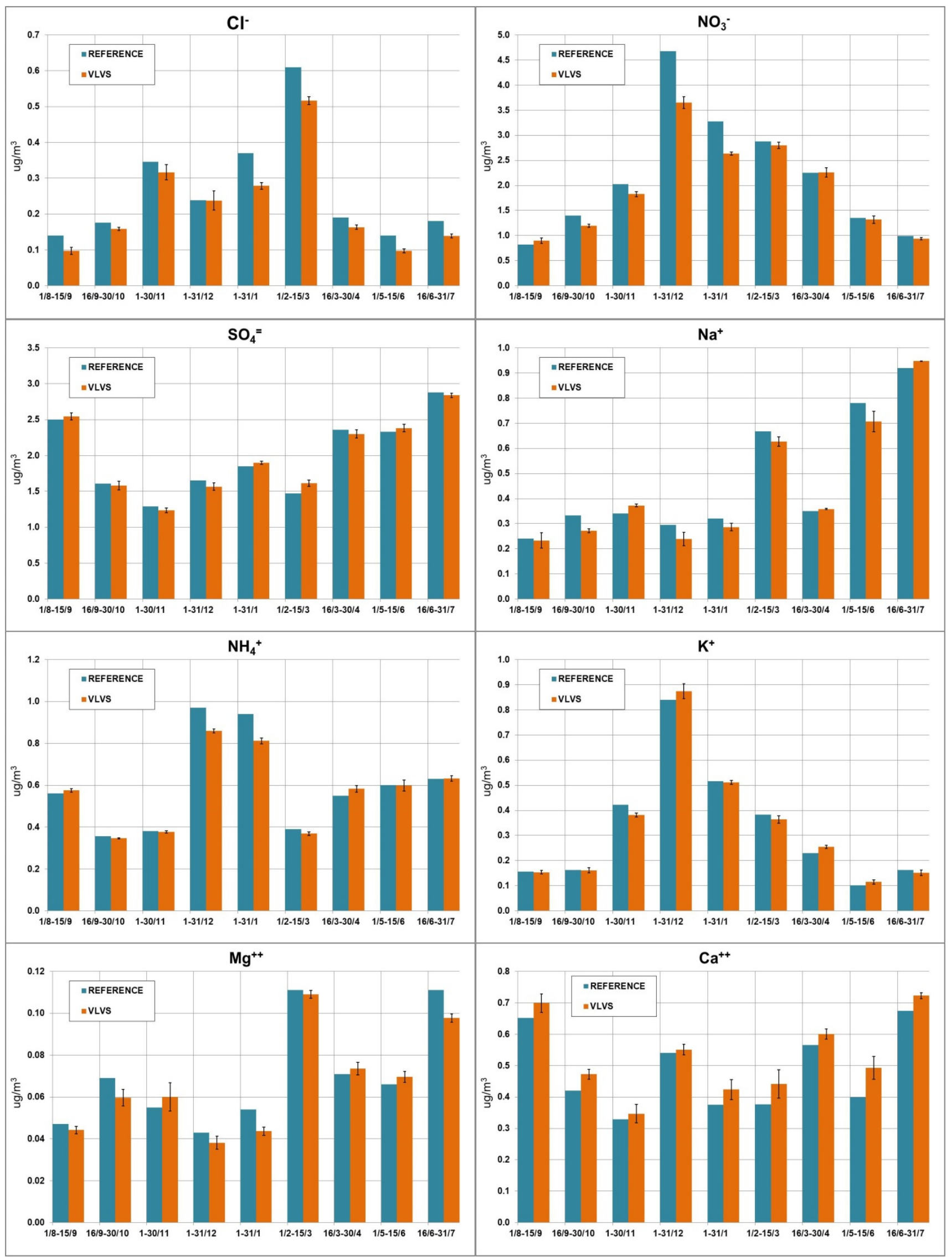

Fig. 3. Comparison of the average results obtained for inorganic ions when sampling $\mathrm{PM}_{10}$ by the VLVSs and by the reference sampler. Standard deviation of the co-located VSVSs is reported as error bar. 


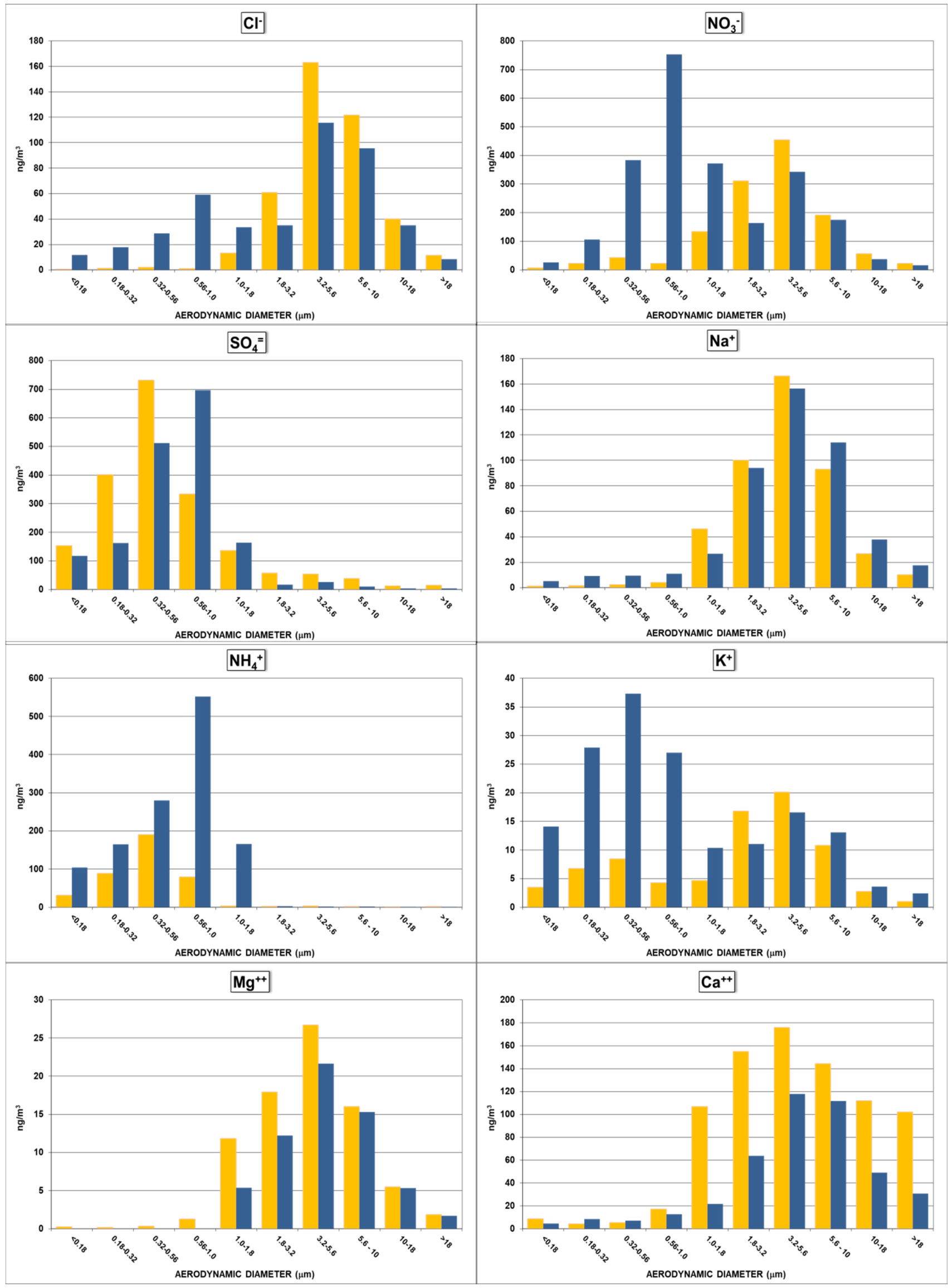

Fig. 4. Size distribution of inorganic ions during the summer (orange bars) and the winter (blue bars) period. 
reference sampler (average of the daily concentration values during the considered period) for the measurement of PAHs is shown in Fig. 5. It is apparent that all the congeners show a seasonal trend characterized by much higher concentration during the cold period. This can be due to both the contribution of a winter source due to biomass combustion in domestic heating and to the possible decomposition of PAHs by atmospheric oxidants, whose concentration increases during the summer.

In order to correctly evaluate the results obtained for PAHs, it is necessary to consider not only their easy oxidation, but also the volatilization of the lower molecular weight congeners. The assessment of the relative importance of the two phenomena is a very difficult goal, as they are influenced by many parameters, among which sampling duration and start time, face velocity, atmospheric temperature and humidity, oxidants concentration, sample composition (Balducci et al., 2018). In air quality studies, some solutions have been identified to obtain the best correspondence between $\mathrm{PAH}$ concentration in the atmosphere and in the collected sample: ozone scrubbers, placed inside the inlet, are used to reduce sample oxidation; back-up polyurethane foams (PUF) are used to recover the amount released during the sampling; the length of the sampling phase is kept as low as possible in order to reduce both artifacts (Schauer et al., 2003; Ravindra et al., 2008; Delgado-Saborit et al., 2013; Paolini et al., 2016).

The VLVSs differ from the reference samplers because of both higher duration of the sampling periods and lower flow rate. In theory, a long sampling duration could favour the release of the most volatile congeners, while, conversely, a lower flow rate could favour their stability. The data reported in Fig. 5 show that we obtained different results for different PAH congeners. For the lighter, 4-ring species, the concentrations determined when sampling with the VLVSs were higher than those obtained when using the reference sampler, with a value of $\mathrm{R}^{-}$as high as $1.5,1.6,1.0$ and 1.2 for fluoranthene, pyrene, benz(a)anthracene and chrysene, respectively (Table 1, last column). For 5-ring and 6-ring congeners, instead, the reverse situation occurred, with $\mathrm{R}$ values below $1(0.79,0.52,0.43,0.67,0.53$ and 0.60 for benzo $(b+j+k)$ fluoranthene, benzo(e)pyrene, benzo(a)pyrene, dibenz(a,h)anthracene, indeno(1,2,3-,c,d)pyrene, and benzo(ghi)perylene, respectively).

From our results, it seems that when the sampling is carried out by using the VLVSs a decrease of the stripping effect, due to the lower linear velocity of the air masses through the filter, prevails for the more volatile $\mathrm{PAH}$ congeners. Loss induced by volatilization is known to be marked for 4-ring PAHs and to be negligible for heavier compounds (Balducci et al., 2018), and this can justify the observed behaviour. Moreover, it is known that the lighter PAHs are size-distributed not only in the fine mode but also in the coarse size range (Lv et al., 2016). For this reason, similarly to what observed for calcium ion, the observed higher VLVS values could also be, in part, a result of the less sharp cut-off curve of the VLVS impactor.

On the other hand, the length of the sampling duration typical of the VSVSs seems to promote degradation and oxidation of the heavier species. These phenomena are known to occur for many PAHs, particularly when sampled on quartz filters, and benzo(a)pirene, which in this study show the lowest $\mathrm{R}^{-}$value (Table 1), is known to be one of the more reactive congeners towards ozone (Balducci et al., 2019).

Although for some congeners and periods the difference between the values obtained by the VSVSs and the reference sampler may be up to two-fold, the results obtained when collecting PAHs by the VLVSs are very repeatable. This reassures the user about obtaining reliable results when using the VLVSs for their typical usage, such as long term assessment and evaluation of spatial gradients. On the other hand, PAHs sampling is so critical and tricky that different procedures will inevitably lead to different results, making the identification of the "right" sampling method a very difficult task.

\section{Levoglucosan}

The repeatability of the measurements of levoglucosan, expressed as standard deviation of the results obtained by the three co-located samples, was very satisfactory: the values were in the range $0.5 \%-10 \%$, with an average of $5.2 \%$ (whole study period).

The comparison between the VLVSs (average of the results obtained by the three co-located samplers) and the reference sampler (average of the daily concentration values during the considered period) for the measurement of levoglucosan is shown in Fig. 6. As in the case of PAHs, the concentration of this compound shows a clear seasonal pattern: during the winter the concentration was about one order of magnitude higher than during the warm period. Levoglucosan is, in fact, a tracer of biomass burning and is released by wild fires, mostly during the warm season, by domestic heating, during the cold season, and, sporadically, by cooking food (barbecue) during the summer (Perrino et al., 2019).

This species is generally considered as a stable compound, and its possible degradation as an action of $\mathrm{OH}$ radical, underlined by some Authors (Lai et al., 2014), has not been detected on particles already collected on the filter substrate. Our data show that levoglucosan does not suffer from the different duration of the samplings, as the comparison with the reference sampler gives very satisfactory results, with a $\overline{\mathrm{R}}$ value of 1.03 .

\section{Elements}

Also in the case of elements the repeatability was very good: for the ten considered elements $(\mathrm{Al}, \mathrm{Cd}, \mathrm{Cs}, \mathrm{Cu}, \mathrm{Fe}$, $\mathrm{K}, \mathrm{Mo}, \mathrm{Pb}, \mathrm{Rb}, \mathrm{V})$ the standard deviation of the results obtained by the three co-located VLVSs was in the range $5.6-16 \%$ (whole study period). In particular, we obtained very satisfactory results (repeatability below $10 \%$, as study average) also for elements whose concentration level is of the order of a few tenths of nanogram per cubic meter: $\mathrm{Cd}$ (range 3.3-16\%) and Cs (range 5.5-17\%). The inferior performance obtained for $\mathrm{Al}$ (range 10-22\%) is also due to the incomplete recovery of this element $(40-50 \%)$ when the $\mathrm{H}_{2} \mathrm{O}_{2} / \mathrm{HNO}_{3}$ mixture is used for acid digestion. However, 

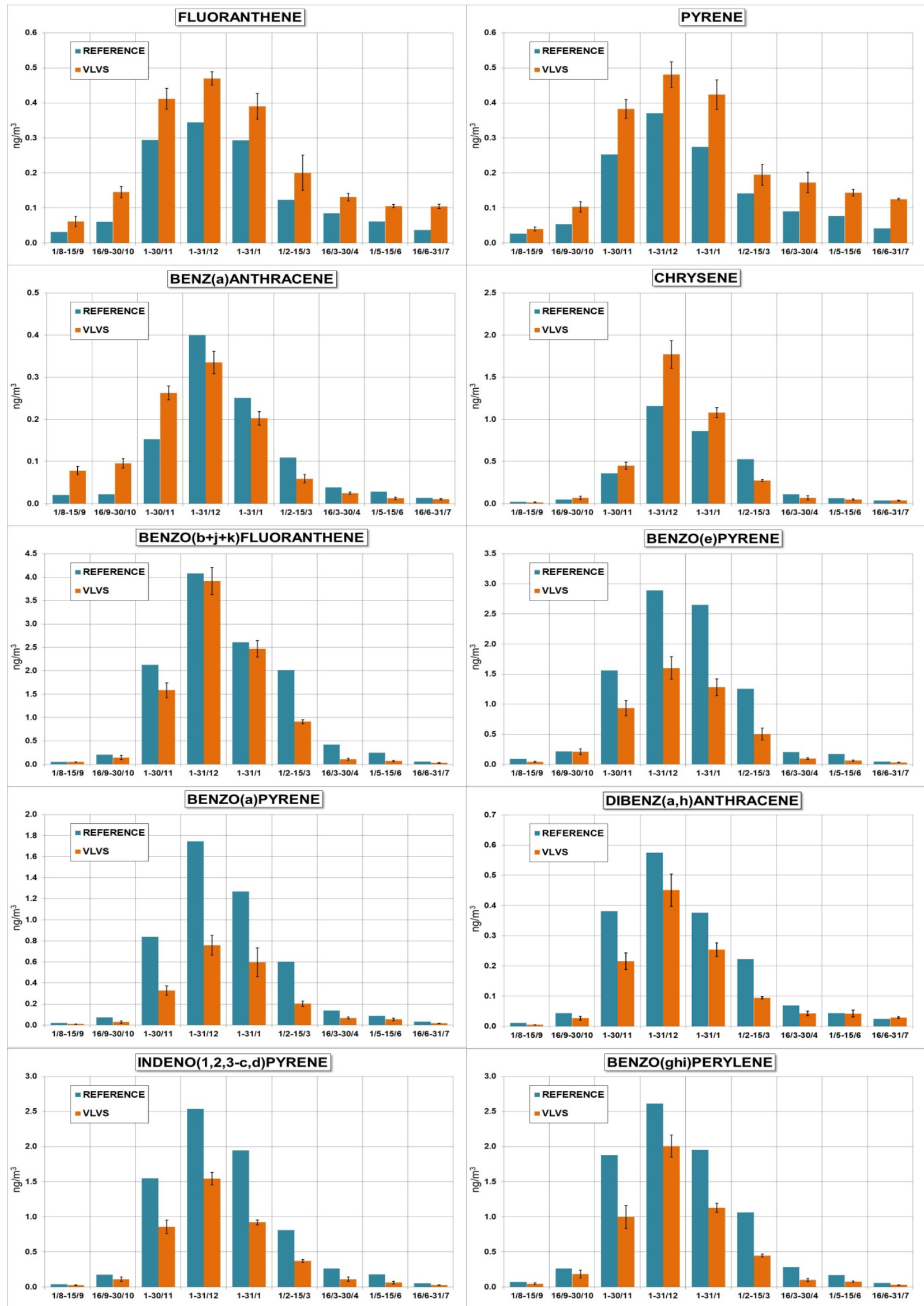

Fig. 5. Comparison of the average results obtained for PAH when sampling $\mathrm{PM}_{10}$ by the VLVSs and by the reference sampler. Standard deviation of the co-located VSVSs is reported as error bar. 


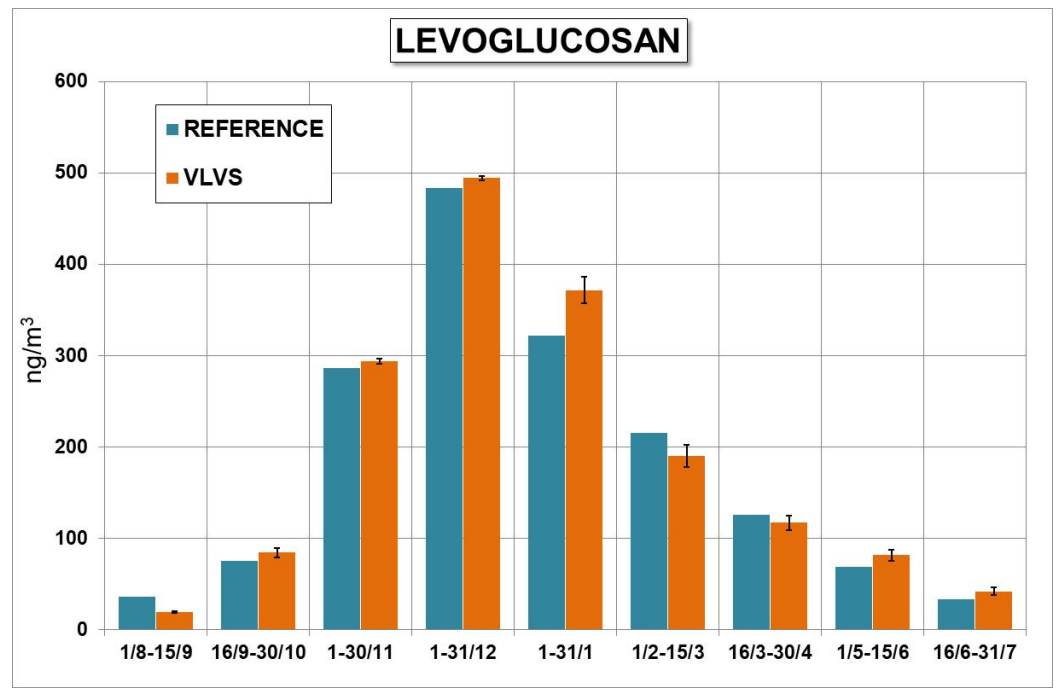

Fig. 6. Comparison of the average results obtained for levoglucosan when sampling $\mathrm{PM}_{10}$ by the VLVSs and by the reference sampler. Standard deviation of the co-located VSVSs is reported as error bar.

the acceptable repeatability of the results indicates a low variability of the recovery percentage.

The comparison between the VLVSs (average of the results obtained by the three co-located samplers) and the reference sampler (average of the daily concentration values during the considered period) for the measurement of elements is shown in Fig. 7. In all cases, the concentration in the samples obtained by the VLVSs and the reference sampler were in good agreement, as it could be expected for these stable chemical components of atmospheric PM (Table 1, last column). The ratio $\mathrm{R}$ ranges from $0.97(\mathrm{Rb})$ to $1.04(\mathrm{Mo})$ and it is very close to one also for elements at very low concentration (1.02 for $\mathrm{Cd}, 1.03$ for $\mathrm{Cs}$ ).

\section{Mass Concentration}

The average mass concentration of $\mathrm{PM}_{10}$ determined by the VLVSs during the nine measurement periods ranged from $14.5 \mu \mathrm{g} \mathrm{m}^{-3}$ (period \#8: May $1^{\text {st }}$-June $15^{\text {th }}$ ) to 35.6 $\mu \mathrm{g} \mathrm{m}^{-3}$ (period \#4: $1^{\text {st }}-31^{\text {st }}$ December). The repeatability of the mass concentration measurements, expressed as standard deviation of the results obtained by the three co-located samples, was in the range $3.0-13 \%$, with an average of $8.2 \%$ (whole study period). These values are worse than those obtained for some PM components (e.g., ions and levoglucosan), probably because the amount of dust collected on the filters was moderately low (between 300 and $850 \mu \mathrm{g}$ ), causing a variability in the results of the gravimetric determinations.

The yearly average concentration of $\mathrm{PM}_{10}$ was $21.3 \mu \mathrm{g} \mathrm{m}^{-3}$ when measured by the VLVSs and $25.2 \mu \mathrm{g} \mathrm{m}^{-3}$ when measured by the reference sampler, with a $\mathrm{R}$ value of 0.84 . During the 9 measurement periods the concentrations obtained when sampling with the VLVSs were always lower than the values obtained by using the reference sampler and $\mathrm{R}$ ranged between 0.73 and 0.97 . There are many possible explanations for this disagreement.

A difference in the mass concentration derives from differences in one or more macro-components of PM, that is, components that constitute a relevant fraction of the PM mass. These includes some elements ( $\mathrm{Al}, \mathrm{Si}, \mathrm{Ca}, \mathrm{Fe}, \mathrm{K}$, $\mathrm{Mg}, \mathrm{Na})$, ions $\left(\mathrm{Cl}^{-}, \mathrm{NO}_{3}^{-}, \mathrm{SO}_{4}{ }^{-}, \mathrm{NH}_{4}{ }^{+}\right)$, and elemental carbon. The remaining PM mass is constituted by microand trace elements and by a huge number of organics, none of which, on its own, constitutes a significant fraction of PM. Concerning the sum of all the macro-components measured in this study, the difference between VLVS and reference sampler was always below $0.3 \mu \mathrm{g} \mathrm{m}^{-3}$, with the only exception of periods \#4 (December: $1.2 \mu \mathrm{g} \mathrm{m}^{-3}$ ) and \#5 (January: $0.81 \mu \mathrm{g} \mathrm{m}^{-3}$ ), two periods when the difference in the determination of ammonium nitrate was predominant. For Si and elemental carbon, the only macro-components not measured in this study, we expect a behaviour similar to elements, with no significant differences between VLVSs and reference sampler. It is thus plausible that the observed differences in PM mass are due to organic species.

Artifacts in sampling organics include many complex issues, some of which may have played a role in this study. These include: face velocity $\left(1.3 \mathrm{~cm} \mathrm{~s}^{-1}\right.$ VLVS vs. $53.5 \mathrm{~cm} \mathrm{~s}^{-1}$ reference sampler), sampling duration (4-6 weeks vs. 1 day), measurement method (gravimetry vs. beta attenuation), filter type (Teflon vs. quartz), site and sampling conditions. These issues have been addressed in many scientific studies (McDow and Huntzicker, 1990; Subramanian et al., 2004; Arhami et al., 2006; Vecchi et al., 2009; Perrino et al., 2013; Cheng and He, 2015, among others) and affect, at a different extent and in various ways, PM samples collected by all instruments, included those operating at $2.3 \mathrm{~m}^{3} \mathrm{~h}^{-1}$. As it is generally assumed that a decrease in face velocity leads to a decrease in volatilization of organics and to an increase in adsorption of organic gases, the low face velocity of the VLVS should not to be the cause of the observed negative differences. Conversely, to our knowledge there are no studies about the effect of a very long sampling duration, which may be the main reason for the observed differences with the reference sampler. Although this issue requires further investigation, it is worth stressing 


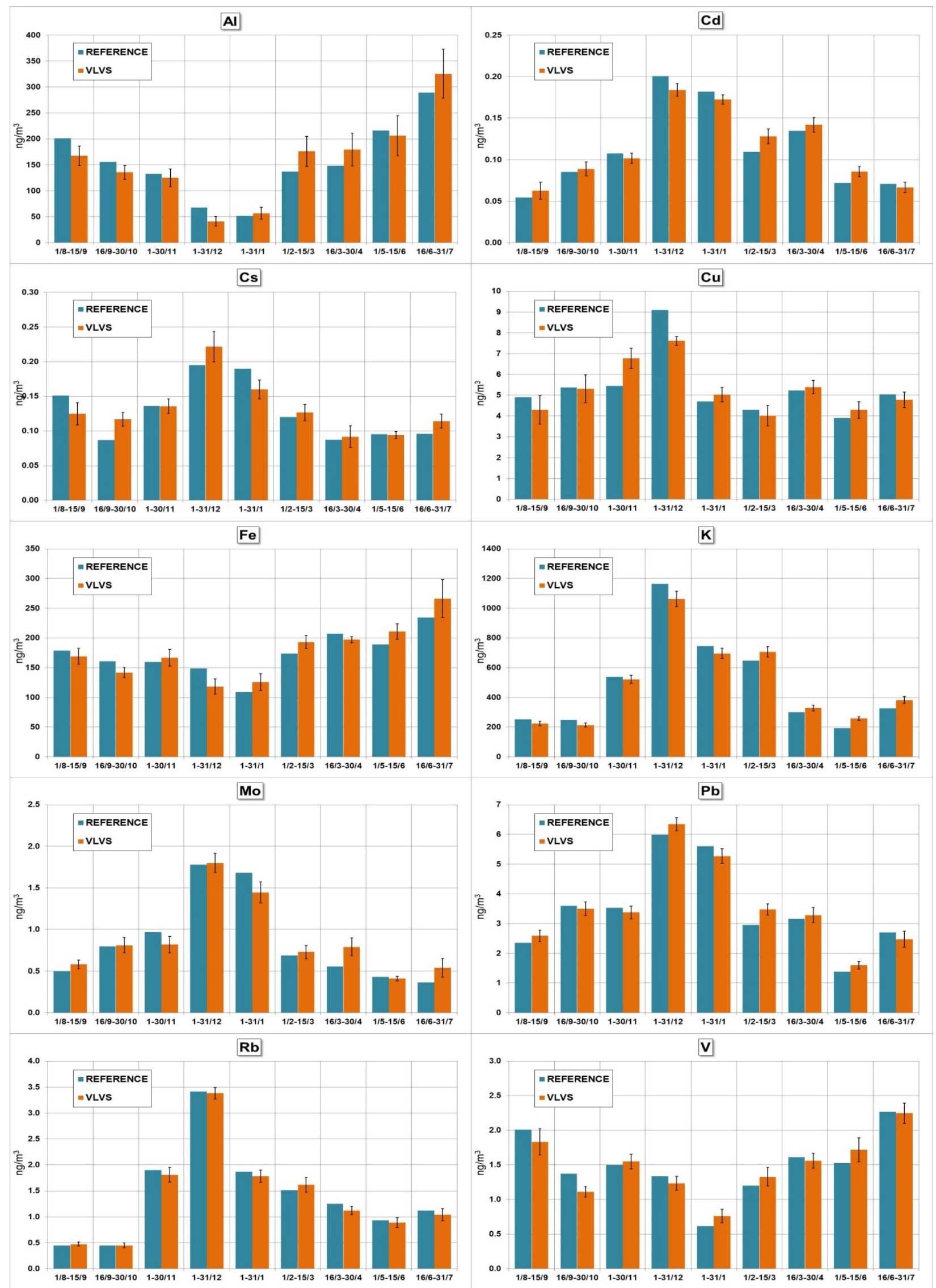

Fig. 7. Comparison of the average results obtained for elements when sampling $\mathrm{PM}_{10}$ by the VLVSs and by the reference sampler. Standard deviation of the co-located VSVSs is reported as error bar. 


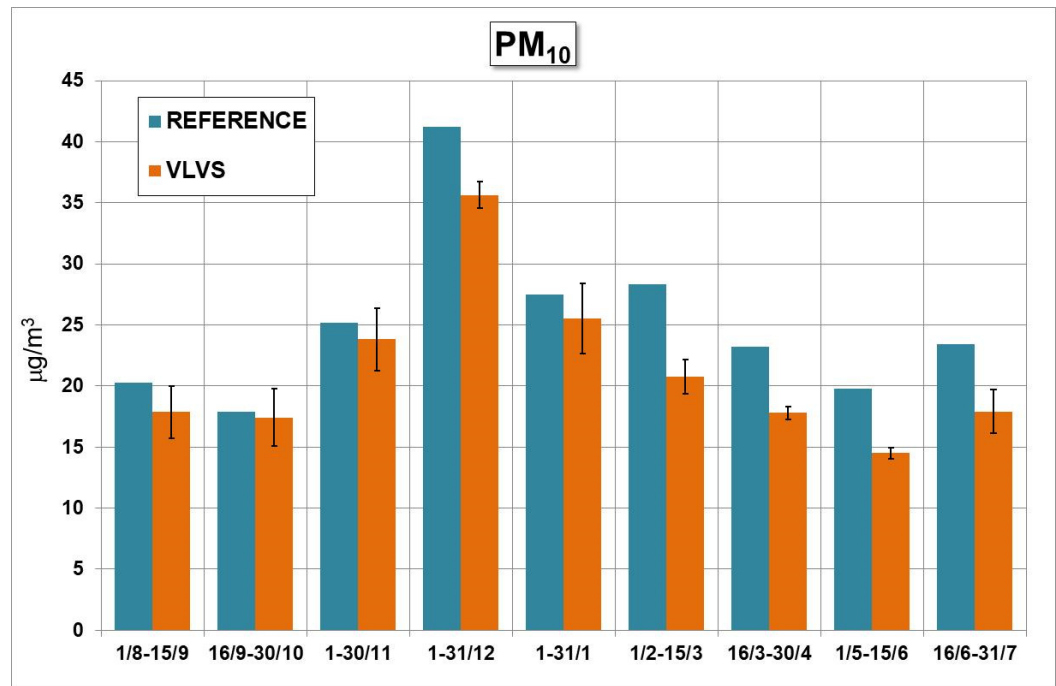

Fig. 8. Comparison of the average results obtained for $\mathrm{PM}_{10}$ mass concentration when sampling by the VLVSs and by the reference sampler. Standard deviation of the co-located VSVSs is reported as error bar.

that the good repeatability results obtained by the VLVSs in the measurement of PM mass allow them to be successfully used in homogeneous networks or for assessing long-term concentration variations also in the presence of artifacts.

\section{CONCLUSIONS}

The performance of a new very-low-volume sampler for atmospheric $\mathrm{PM}$ (flow rate: $0.5 \mathrm{~L} \mathrm{~min}^{-1}$; typical sampling period: 1-2 months) was evaluated. The repeatability in the sampled volume was excellent (below 0.1\%). The repeatability in the measurement of the concentration of PM and of all the considered chemical components (ions, $\mathrm{PAH}$, levoglucosan, elements) was very satisfactory $(8.2 \%$ for PM mass, $2.0-5.5 \%$ for ions, $10-17 \%$ for PAH, $5.2 \%$ for levoglucosan and 5.6-16\% for elements). These good results suggest the use of the VLVSs to draw concentration maps, to assess the spatial variability and to evaluate timeweighted concentration of PM and PM components.

The comparison with a reference sampler working at $2.3 \mathrm{~m}^{3} \mathrm{~h}^{-1}$ gave satisfactory results (VLVS/REF in the range 0.94-1.1) for levoglucosan, elements and ions, with the only exception of ammonium nitrate $(0.93)$ and ammonium chloride $(0.83)$. The results obtained for PAH were more variable and seem to depend on the molecular complexity of the congeners. Positive and negative artifact in the sampling of organics are probably responsible for the lower values obtained in the determination of PM mass concentration when sampling with the VLVSs.

Our results show that the VLVSs constitute a cheap and valuable tool to evaluate long-term concentration variations, time-weighted exposure and local sources of PM and of its chemical components.

\section{ACKNOWLEDGEMENTS}

The Authors gratefully thanks S. Dalla Torre, M. Giusto, S. Pareti, E. Rantica and M.C. Tomasi Scianò for their technical assistance during the sampling and the analytical phases of this work.

\section{REFERENCES}

Arhami, M., Kuhn, T., Fine, P.M., Delfino, R.J. and Sioutas, C. (2006). Effects of sampling artifacts and operating parameters on the performance of a semicontinuous particulate elemental carbon/organic carbon monitor. Environ. Sci. Technol. 40: 945-954.

Ashbaugh, L.L. and Eldred, R.A. (2004). Loss of particle nitrate from teflon sampling filters: Effects on measured gravimetric mass in California and in the IMPROVE network. J. Air Waste Manage. Assoc. 54: 93-104.

Balducci, C., Cecinato, A., Paolini, V., Guerriero, E., Perilli, M., Romagnoli, P., Tortorella, C., Iacobellis, S., Giove, A. and Febo, A. (2018). Volatilization and oxidative artifacts of PM bound PAHs collected at low volume sampling (1): Laboratory and field evaluation. Chemosphere 200: 106-115.

Canepari, S., Astolfi, M.L., Catrambone, M., Frasca, D., Marcoccia, M., Marcovecchio, F., Massimi, L., Rantica, E. and Perrino, C. (2019). A combined chemical/size fractionation approach to study winter/summer variations, ageing and source strength of atmospheric particles. Environ. Pollut. 253: 19-28.

Cheng, Y. and He, K.B. (2015). Measurement of carbonaceous aerosol with different sampling configurations and frequencies. Atmos. Meas. Tech. 8: 2639-2648.

Chow, J.C., Doraiswamy, P., Watson, J.G., Chen, L.W.A., Ho, S.S.H. and Sodeman, D.A. (2008). Advances in integrated and continuous measurements for particle mass and chemical composition. J. Air Waste Manage. Assoc. 58: 141-163.

Costabile, F., Alas, H., Aufderheide, M., Avino, P., Amato, F., Argentini, S., Barnaba, F., Berico, M., Bernardoni, V., Biondi, R., Casasanta, G., Ciampichetti, 
S., Calzolai, G., Canepari, S., Conidi, A., Cordelli, E., Di Ianni, A., Di Liberto, L., Facchini, C.M., Facci, A., Frasca, D., Gilardoni, S., Grollino, G.M., Gualtieri, M., Lucarelli, F., Malaguti, A., Manigrasso, M., Montagnoli, M., Nava, S., Perrino, C., Padoan, E., Petenko, I., Querol, X., Simonetti, G., Tranfo, G., Ubertini, S., Valli, G., Valentini, S., Vecchi, R., Volpi, F., Weinhold, K., Wiedensohler, A., Zanini, G., Gobbi, P.G. and Petralia, E. (2017). First results of the "Carbonaceous aerosol in Rome and Environs (CARE)" experiment: Beyond current standards for $\mathrm{PM}_{10}$. Atmosphere 8: 249.

Delgado-Saborit, J.M., Stark, C. and Harrison, R.M. (2013). Use of a versatile high efficiency multiparallel denuder for the sampling of PAHs in ambient air: Gas and particle phase concentrations, particle size distribution and artifact formation Environ. Sci. Technol. 48: 499507.

European Standard EN 12341 (2014). Ambient air Standard gravimetric measurement method for the determination of the $\mathrm{PM}_{10}$ or $\mathrm{PM}_{2.5}$ mass concentration of suspended particulate matter, European Committee for Standardization (CEN).

Hasenfratz, D., Saukh, O., Walser, C., Hueglin, C., Fierz, M., Arn, T., Beutel, J. and Thiele, L. (2015). Deriving high-resolution urban air pollution maps using mobile sensor nodes. Pervasive Mob. Comput. 16: 268-285.

Lai, C., Liu, Y., Ma, J. and He, H. (2014). Degradation kinetics of levoglucosan initiated by hydroxyl radical under different environmental conditions. Atmos. Environ. 91: 32-39.

Lv, Y., Li, X., Xu, T. T., Cheng, T. T., Yang, X., Chen, J. M., Iinuma, Y. and Herrmann, H. (2016). Size distributions of polycyclic aromatic hydrocarbons in urban atmosphere: Sorption mechanism and source contributions to respiratory deposition. Atmos. Chem. Phys. 16: 29712983.

Marć, M., Tobiszewski, M., Zabiegała, B., de la Guardia, M. and Namieśnik, J. (2015). Current air quality analytics and monitoring: A review. Anal. Chim. Acta 853: 116126

Massimi, L., Ristorini, M., Eusebio, M., Florendo, D., Adeyemo, A., Brugnoli, D. and Canepari, S. (2017). Monitoring and evaluation of Terni (Central Italy) air quality through spatially resolved analyses. Atmosphere 8: 200-213.

McAlary, T., Groenevelt, H., Disher, S., Arnold, J., Seethapathy, S., Sacco, P., Crump, D., Schumacher, B., Hayes, H., Johnson, P. and Górecki, T. (2015). Passive sampling for volatile organic compounds in indoor aircontrolled laboratory comparison of four sampler types. Environ. Sci. Processes Impacts 17: 896-905.

McDow, S.R. and Huntzicker, J.J. (1990). Vapor adsorption artifact in the sampling of organic aerosol: Face velocity effects. Atmos. Environ. 24: 2563-2571.
Nava, S., Prati, P., Lucarelli, F., Mandò, P.A. and Zucchiatti, A. (2002). Source apportionment in the town of La Spezia (Italy) by continuous aerosol sampling and PIXE analysis. Water Air Soil Pollut. Focus 2: 247-260.

Paolini, V., Guerriero, E., Bacaloni, A., Rotatori, M., Benedetti, P. and Mosca, S. (2016). Simultaneous sampling of vapor and particle-phase carcinogenic polycyclic aromatic hydrocarbons on functionalized glass fiber filters. Aerosol Air Qual. Res. 16: 175-183.

Perrino, C., Marconi, E., Tofful, L., Farao, C., Materazzi, S. and Canepari, S. (2012). Thermal stability of inorganic and organic compounds in atmospheric particulate matter. Atmos. Environ. 54: 36-43.

Perrino, C., Canepari, S. and Catrambone, M. (2013). Comparing the performance of Teflon and quartz membrane filters collecting atmospheric PM: Influence of atmospheric water. Aerosol Air Qual. Res. 13: 137147.

Perrino, C., Tofful, L., Dalla Torre, S., Sargolini, T. and Canepari, S. (2019). Biomass burning contribution to $\mathrm{PM}_{10}$ concentration in Rome (Italy): Seasonal, daily and two-hourly variations. Chemosphere 222: 839-848.

Ravindra, K., Sokhi, R. and Van Grieken, R. (2008). Atmospheric polycyclic aromatic hydrocarbons: Source attribution, emission factors and regulation. Atmos. Environ. 42: 2895-2921.

Reichmuth, A., Wunderli, S., Weber, M. and Meyer, V.R. (2004). The uncertainty of weighing data obtained with electronic analytical balances. Microchim. Acta 148: 133-141.

Rohde, R.A. and Muller, R.A. (2015). Air pollution in China: Mapping of concentrations and sources. PLoS One 10: 0135749.

Schauer, C., Niessner, R. and Pöschl, U. (2003). Polycyclic aromatic hydrocarbons in urban air particulate matter: Decadal and seasonal trends, chemical degradation, and sampling artifacts. Environ. Sci. Technol. 37: 28612868.

Subramanian, R., Khlystov, A.Y., Cabada, J.C. and Robinson, A.L. (2004). Positive and negative artifacts in particulate organic carbon measurements with denuded and undenuded sampler configurations special issue of aerosol science and technology on findings from the fine particulate matter supersites program. Aerosol Sci. Technol. 38: 27-48.

Vecchi, R., Valli, G., Fermo, P., D'Alessandro, A., Piazzalunga, A. and Bernardoni, V. (2009). Organic and inorganic sampling artifacts assessment. Atmos. Environ. 43: 1713-1720. 